\title{
PENGARUH TEKNIK RELAKSASI NAFAS TERHADAP PENURUNAN TINGKAT NYERI DISMENORE
}

\section{(Pada Mahasiswi Tingkat 1 Fakultas Ekonomi Universitas Islam Lamongan)}

\author{
Oniek Lestari, S.Kes, M.Kes* \\ *Dosen Program Studi Fakultas Ekonomi Universitas Islam Lamongam
}

\section{RINGKASAN}

Dismenore merupakan masalah tersendiri yang banyak dialami kaum wanita ketika menstruasi tiba. Dismenore adalah nyeri menjelang atau selama menstruasi yang biasanya terbatas pada perut bawah tetapi dapat juga menyebar kepinggang, punggung dan paha sehingga memaksa penderita untuk beristirahat. Berdasarkan survey awal didapatkan 50\% mahasiswi Fakultas Ekonomi Universitas Islam Lamongan Tingkat I. Untuk mengatasi masalah tersebut diperlukan suatu penanganan agar aktivitas sehari-hari dapat berjalan dengan lancar.

Tujuan penelitian ini adalah mencari pengaruh teknik relaksasi nafas terhadap penurunan tingkat nyeri. Desain penelitian ini menggunakan metode Pra Eksperimen (One Group Pretest-Postest Design). Metode sampling yang digunakan adalah simple random sampling. Sampel yang diambil sebanyak 30 responden yaitu mahasiswi tingkat I yang Dismenore pada bulan Januari sampai Pebruari 2016. Data penelitian ini diambil dengan menggunakan skala nyeri Bourbanis dan lembar observasi. Setelah ditabulasi data yang ada dianalisa dengan menggunakan uji Wilcoxon Sign Rank Test dengan tingkat signifikansi 0,05 .

Hasil penelitian menunjukkan bahwa setelah diberi Teknik relaksasi nafas tingkatan nyeri Dismenore berkurang sebanyak 24 orang dan yang tingkatan nyerinya tetap sebanyak 4 orang. Sedangkan dari hasil pengujian statistik diperoleh hasil ada pengaruh tingkatan nyeri Dismenore dengan teknik relaksasi nafas dimana nilai Z hitung sebesar $-5,014$ dengan tingkat signifikansi $0,000(p<0,05)$. Dari hasil penelitian ini didapatkan ada pengaruh teknik relaksasi nafas terhadap penurunan tingkat nyeri Dismenore.

Oleh karena itu hendaknya para wanita yang mengalami Dismenore agar menggunakan teknik relaksasi nafas untuk menurunkan rasa nyeri.

\section{Kata kunci : Nyeri Dismenore, Teknik Relaksasi Nafas, Mahasiswa}

\section{PENDAHULUAN}

Dismenore merupakan nyeri

hebat menjelang atau selama

menstruasi sehingga memaksa

penderita untuk beristirahat dan meninggalkan pekerjaan atau cara hidupnya sehari-hari untuk beberapa jam atau hari. Bersamaan dengan rasa nyeri dapat juga dijumpai rasa mual, muntah, sakit kepala, diare dan sebagainya (Hanifa Wiknjosastro, 2005:229).

Nyeri pada Dismenore primer diduga berasal dari kontraksi rahim yang dirangsang oleh prostaglandin. Nyeri dirasakan semakin hebat ketika bekuan atau potongan jaringan dari lapisan rahim melewati serviks (leher 
rahim), terutama jika saluran serviksnya sempit. Faktor lainnya yang bisa memperburuk Dismenore adalah: Rahim yang menghadap ke belakang (retroversi), Kurang berolah raga, Stres psikis atau stres social (Ninik Dwi A, 2005).

Pada umumnya setiap wanita akan mengalami gejala-gejala seperti malas, lemas, payudara mengejang, dan nyeri di sekitar perut bagian bawah sebelum atau saat mengalami haid. Bahkan ada juga wanita yang mengalami nyeri di perut sampai kram perut, mual, nyeri kepala, sehingga gak bisa melakukan aktivitas sehari-hari bahkan sampai pingsan seperti yang kamu alami. Gejala (premenstrual syndrom) PMS yang berat seperti ini disebut dengan dismenorrhoe. Karena memang dismenorrhoe bisa berkaitan dengan gejala adanya gangguan pada organ reproduksi. Namun ada juga dismenorrhoe yang hanya disebabkan karena kondisi tubuh yang sedang kurang sehat, baik secara fisik maupun psikologis. Misalnya sedang sakit, maupun sedang mengalami stres yang berlebihan. Tetapi jika kondisinya seperti ini tentu saja dismenorrhoe tidak akan dialami setiap bulan setiap kali mengalami haid. (Adhyos Aulia. 2006)

Dismenore menjadi satu masalah tersendiri yang banyak dialami kaum wanita sekitar 60-75\% wanita muda mengalaminya. Tiga perempat wanita yang mengalaminya intensitas kram ringan atau sedang, tetapi $25 \%$ nyerinya hebat dan membuat penderita tidak berdaya (Liewellyn-Jones Derek, 2002:216).

Banyak kebudayaan percaya bahwa haid dikendalikan oleh bulan dan cairan haid bersifat toksik. Di zaman modern, telah terbukti bahwa cairan haid mengandung zat-zat ini telah dibuktikan adalah prostaglandin. (Hacker/moore 2001,45).

Bagi wanita yang normal dan sehat, pada usia tertentu akan mengalami haid. Didalam prakteknya, banyak wanita yang sedang dalam masa haid tetap bekerja tanpa gangguan apapun. Tetapi kalau keadaan fisiknya tidak memungkinkan sehingga yang bersangkutan tidak dapat melakukan pekerjaan tersebut. Hal ini diatur dalam UU No. 1 tahun 1951, pasal 13 ayat 1 dinyatakan: Buruh wanita tidak boleh diwajibkan bekerja pada hari pertama dan hari kedua waktu haid. Pelaksaan dari ketentuan tersebut diatur dalam peraturan pemerintah No. 4 tahun 1951, pasal 1 sub pasal 1 ayat 2 : dalam menjalankan aturan tersebut dalam UU No. 1 tahun 1951 pasal 13 ayat 1 , maka majikan dianggap tidak mengetahui tentang keadaan haid dari buruhnya, bila yang bersangkutan tidak memberitahukan hal itu kepadanya. (Ninik Dwi A, 2005)

Uterus dipersyarafi oleh sistem syaraf otonom yang terdiri dari syaraf simpatis dan parasimpatis. Jeffcoate mengemukakan bahwa Dismenorea ditimbulkan oleh ketidak seimbangan pengendalian sistem syaraf otonom terhadap miometrium. Pada keadaan ini terjadi perangsangan yang berlebihan oleh syaraf simpatis sehingga serabut-serabut sirkuler pada istmus dan ostium uteri internum menjadi hipertonik. Teknik relaksasi memberikan individu kontrol diri ketika terjadi rasa tidak nyaman atau nyeri, stress fisik dan emosi pada nyeri (Potter Patricia, 2006:1528). 
Dengan merelaksasikan otototot skelet yang mengalami spasme yang disebabkan oleh peningkatan prostaglandin sehingga terjadi vasodilatasi pembuluh darah dan akan meningkatkan aliran darah ke daerah yang mengalami spasme dan iskemic sehinnga dapat meredahkan nyeri.

Seperti halnya dengan rasa nyeri yang lain, Dismenore juga memerlukan penanganan sehingga aktivitas sehari-hari tetap dilanjutkan. Wanita yang pernah mengalami Dismenore mungkin sudah pernah mencoba beberapa cara untuk menghilangkan rasa nyeri dengan mendapat obat-obat tertentu yang tidak terlalu membantu dan ada beberapa yang memberikan kesembuhan dramatis, dan yang lain bisa mengurangi nyeri sampai batas yang dapat ditanggung, tapi ada yang tidak memberikan efek sama sekali atau malah memberikan efek samping yang tidak disukai sehingga memaksa penderita untuk beristirahat dan meninggalkan pekerjaan sehingga diperlukan perawatan khusus untuk mengurangi rasa nyeri.

Salah satu hasil penelitian yang lalu dilaksanakan di panti asuhan yatim putri ilsam Yogyakarta dengan jumlah sample 30 orang mendapat kesimpulan ada pengaruh yang signifikan pemberian teknik relaksaksasi nafas terhadap penurunan nyeri disminore. (Ninik Dwi A, 2005).

Berdasarkan survei awal yang dilakukan dari 43 mahasiswi Fakultas Ekonomi tingkat 1, yang mengalami Dismenore pada bulan oktober 2005 berjumlah 22 mahasiswi, 10 (45\%) mahasiswi mengalami Dismenore kadang-kadang dan $12 \quad(55 \%)$ mahasiswi mengalami Dismenore tiap bulan. Pada survei yang dilakukan pada mahasiswi dengan Dismenore $30 \%$ diantaranya diatasi dengan obatobatan, $20 \%$ diantaranya diatasi dengan beraktivitas dan 50\% diantaranya dibiarkan saja atau tidak diapa-apakan.

Metode penanganan nyeri banyak berkembang, metode non farmakologi adalah salah satu metode yang digemari masyarakat karena tidak membutuhkan obat-obatan atau alat tertentu serta mudah didapat dan mampu dilakukan sendiri. Banyak cara untuk mengatasi sakit ini, tapi tindakan sederhana yang telah lama diketahui sebagai metode yang efektif adalah Salah satu intervensi kebidanan untuk menurunkan nyeri adalah pengalihan perhatian. Dimana tehnik ini dengan memfokuskan diri kepada lingkungan. Lingkungan yang sangat tenang dan sedikit membangkitkan input sensori. Perhatian harus cukup kuat untuk melibatkan seluruh perhatian yang tidak menjemukan. Nyeri yang diderita sangat luas memerlukan berbagai penarik perhatran yang berarti. Metode menarik perhatian yang digunakan yaitu tehnik nafas dalam (Ninik Dwi A, 2005)

Berdasarkan latar belakang diatas, maka masalah dalam penelitian ini adalah tingginya angka Dismenore pada mahasisiwi tingkat 1 Fakultas Ekonomi Universitas Islam Lamongan

\section{TUJUAN PENELITIAN}

Diketahuinya pengaruh teknik relaksasi nafas terhadap penurunan tingkat nyeri Dismenore

\section{TINJAUAN PUSTAKA}

Menstruasi adalah perdarahan periodik pada uterus yang dimulai 
sekitar 14 hari setelah ovulasi (Bobak, 2004).

Menstruasi adalah perdarahan vagina secara berkala akibat terlepasnya lapisan endometrium uterus. Fungsi menstruasi normal merupakan hasil interaksi antara hipotalamus, hipofisis, dan ovarium dengan perubahan-perubahan terkait pada jaringan sasaran pada saluran reproduksi normal, ovarium memainkan peranan penting dalam proses ini, karena tampaknya bertanggung jawab dalam pengaturan perubahan-perubahan siklik maupun lama siklus menstruasi (Greenspan, 1999).

Dismenore adalah nyeri hebat menjelang atau selama menstruasi sehingga memaksa penderita untuk beristirahat dan meninggalkan pekerjaan atau cara hidupnya seharihari untuk beberapa jam / hari (Hanifa W, 2005:229).

Dismenore adalah nyeri menjelang atau selama haid, sampai membuat wanita tersebut tidak dapat bekerja dan hams tidur (Arif Mansjoer, 2005:372).

Menurut Scrumum dalam A. Aziz Alimul H. (2006:214) nyeri adalah suatu keadaan yang tidak menyenangkan akibat terjadinya rangsangan fisik maupun dari serabut saraf dalam tubuh ke otak dan diikuti oleh reaksi fisik, fisiologi dan emosional.

Nyeri adalah suatu proses dinamik yaitu hubungan fisiologik antara rangsangan nyeri dan keluaran sensorik respon nyeri dapat mengalami modifikasi seiring dengan waktu (Price Sylvia Ander son, 2006:1101).

Nyeri adalah suatu sensorik subyektif dan pengalaman emosional yang tidak menyenangkan berkaitan dengan kerusakan jaringan yang aktual atau potensial yang dirasakan dalam kejadian-kejadian dimana terjadi kerusakan (Potter Patricia, 2006:1502).

Teknik relaksasi nafas dalam merupakan suatu bentuk asuhan keperawatan, yang dalam hal ini perawat mengajarkan kepada klien bagaimana cara melakukan napas dalam, napas lambat (menahan inspirasi secara maksimal) dan bagaimana menghembuskan napas secara perlahan, Selain dapat menurunkan intensitas nyeri, teknik relaksasi napas dalam juga dapat meningkatkan ventilasi paru dan meningkatkan oksigenasi darah (Smeltzer \& Bare, 2002).

Smeltzer \& Bare (2002) menyatakan bahwa tujuan teknik relaksasi napas dalam adalah untuk meningkatkan ventilasi alveoli, memelihara pertukaran gas, mencegah atelektasi paru, meningkatkan efesiensi batuk, mengurangj stress baik stress fisik maupun emosional yaitu menurunkan intensitas nyeri dan menurunkan kecemasan.

\section{METODE PENELITIAN}

Desain penelitian yang digunakan adalah Pra-Eksperimental (One Group PratestPosttest Design) yaitu kelompok subyek diobservasi sebelum dilakukan intervensi kemudian diobservasi lagi setelah intervensi (Nursalam, 2003 :88).

Uji statistik yang digunakan adalah Uji Wilcoxon Sign Rank Test. Uji ini merupakan penyempurnaan dari uji tanda. Kalau dalam uji yanda besranya selisih nilai positif dan negative tidak diperhitungkan. Sedangkan dalam Uji Wilcoxon Sign 
Rank Test ini diperhitungkan. (sugiono, 2006 : 131).

\section{HIPOTESIS}

Terdapat Pengaruh Teknik Relaksasi Nafas Terhadap Penurunan Tingkat Nyeri Dismenore

\section{HASIL PENELITIAN}

Hasil penelitian ini didapatkan dari proses pengumpulan data melalui skala nyeri bourbanis dan lembar observasi. Penyajian meliputi data umum dan khusus.

Data khusus ini meliputi mengidentifikasi tingkatan nyeri Dismenore pada mahasiswi sebelum diberi teknik relaksasi nafas, mengidentifikasi tingkatan nyeri Dismenore pada mahasiswi setelah diberi teknik relaksasi nafas, selanjutnya menganalisis pengaruh teknik relaksasi nafas pada mahasiswi terhadap tingkat nyeri Dismenore

a. Mengidentifikasi tingkatan nyeri Dismenore pada mahasiswi sebelum diberi teknik relaksasi nafas.

Data tentang gambaran tingkatan nyeri Dismenore pada mahasiswi sebelum diberi teknik relaksasi nafas dapat dilihat pada tabel 1.1. berikut ini :

Tabel 1.1. Distribusi frekuensi tingkatan nyeri Dismenore pada mahasiswi tingkat I Fakultas Ekonomi Universitas Islam Lamongan sebelum diberi teknik relaksasi nafas bulan Januari sampai Pebruari tahun 2016.

\begin{tabular}{|c|c|c|c|}
\hline No & Tingkatan nyeri & Jumlah & $(\%)$ \\
\hline 1 & Nyeri ringan & 18 & 60 \\
\hline 2 & Nyeri sedang & 11 & 36,7 \\
\hline
\end{tabular}

\begin{tabular}{|c|l|c|c|}
\hline 3 & Nyeri berat & 1 & 3,3 \\
\hline \multicolumn{2}{|c|}{ Total } & 30 & 100 \\
\hline
\end{tabular}

Berdasarkan data dari tabel 1.1. diatas dari 30 responden didapatkan sebagian besar responden sebelum diberi teknik relaksasi nafas mengalami nyeri Dismenore ringan yaitu sebanyak 18 orang $(60 \%)$ dan hanya sebagian kecil yang mengalami nyeri Dismenore berat yaitu sebanyak 1 orang $(3,3 \%)$.

b. Mengidentifikasi tingkatan nyeri Dismenore pada mahasiswi setelah diberi teknik relaksasi nafas

Data tentang mengidentifikasi tingkatan nyeri Dismenore pada mahasiswi setelah diberi teknik relaksasi nafas dapat dilihat pada tabel 1.2. berikut ini :

Tabel 1.2. Distribusi frekuensi tingkatan nyeri Dismenore pada mahasiswi setelah diberi teknik relaksasi nafas bulan Januari sampai Pebruari tahun 2016

\begin{tabular}{|c|c|c|c|}
\hline No & $\begin{array}{c}\text { Tingkatan } \\
\text { nyeri }\end{array}$ & Jumlah & $(\%)$ \\
\hline 1 & Tidak nyeri & 16 & 53,3 \\
\hline 2 & Nyeri ringan & 12 & 40 \\
\hline 3 & Nyeri sedang & 2 & 6,7 \\
\hline \multicolumn{2}{|c|}{ Total } & 30 & 100 \\
\hline
\end{tabular}

Berdasarkan data dari tabel 1.2. diatas, dari 30 responden didapatkan sebagian besar responden setelah diberi teknik relaksasi nafas tidak merasa nyeri lagi yaitu sebanyak 16 orang $(53,3 \%)$ dan hanya sebagian kecil yang masih mengalami nyeri Dismenore sedang yaitu sebanyak 2 orang $(6,7 \%)$ 


\section{c. Uji statistik pengaruh teknik relaksasi terhadap tingkat nyeri Dismenore}

Berdasarkan

hasil

pengumpulan data diperoleh data berupa tingkatan nyeri Dismenore, data tersebut kemudian dianalisa untuk mengetahui adakah pengaruh teknik relaksasi terhadap tingkat nyeri Dismenore. Untuk menganalisa pengaruh tingkatan nyeri Dismenore tersebut maka dilakukan uji statistik Wilcoxon Sign Rank Test. Hasil uji statistik Wilcoxon Sign Rank Test tentang pengaruh teknik relaksasi terhadap tingkat nyeri Dismenore pada mahasiswi sebelum diberi teknik relaksasi nafas dan sesudah diberi teknik relaksasi nafas dapat dilihat pada tabel 1.3. berikut ini

\section{Tabel 1.3. Pengaruh Teknik Relaksasi Terhadap Tingkat Nyeri Dismenore Bulan Januari Sampai Pebruari tahun 2016 DiFakultas Ekonomi Universitas Islam Lamongan}

\begin{tabular}{|c|c|c|c|c|c|}
\hline \multirow[t]{2}{*}{ No } & \multirow{2}{*}{$\begin{array}{l}\text { Tingkat nyeri } \\
\text { sebelum } \\
\text { dilakukan } \\
\text { teknik } \\
\text { relaksasi } \\
\text { nafas }\end{array}$} & \multicolumn{3}{|c|}{$\begin{array}{l}\text { Pengaruh nyeri setelah } \\
\text { dilakukan } \\
\text { teknik relaksasi nafas }\end{array}$} & \multirow[t]{2}{*}{ Jumlah } \\
\hline & & $\begin{array}{l}\text { Berkur } \\
\text { ang }\end{array}$ & Menetap & $\begin{array}{c}\text { berta } \\
\text { mba } \\
\mathrm{h}\end{array}$ & \\
\hline 1 & Nyeri Ringan & $\begin{array}{c}15 \\
(50 \%)\end{array}$ & $3(10 \%)$ & - & $18(60 \%)$ \\
\hline 2 & Nyeri Sedang & $\begin{array}{c}10 \\
(33,4 \% \\
)\end{array}$ & $1(3,3 \%)$ & - & $\begin{array}{c}11(36,7 \% \\
)\end{array}$ \\
\hline 3 & Nyeri Berat & $\begin{array}{c}1 \\
(3,3 \%)\end{array}$ & - & - & $1(3,3 \%)$ \\
\hline & Jumlah & $\begin{array}{c}26 \\
(86,7 \% \\
\quad) \\
\end{array}$ & $\begin{array}{c}4 \\
(13,3 \%)\end{array}$ & & $\begin{array}{c}30(100 \% \\
)\end{array}$ \\
\hline & & ung $-5,01$ & table & & \\
\hline
\end{tabular}

Tabel 1.3. di atas menunjukkan bahwa dari 30 responden seabagian besar tingkatan nyerinya berkurang sebanyak $26(86,7 \%)$ dan sebagian kecil nyerinya menetap $4(13,3 \%)$ responden..

Dari hasil statistik dapat diketahui bahwa hasil uji statistik Wilcoxon Sign Rank Test menunjukkan nilai signifikansi $(p$ sign $=0,000)$ dimana $\mathrm{Z}$ hitung $=$ $[-5,014] \mathrm{Z}$ tabel $=1,99$ hal ini berarti p sign $<0,05$ dan $\mathrm{Z}$ hitung $>\mathrm{Z}$ tabel sehingga $\mathrm{H}_{1}$ diterima artinya ada pengaruh teknik relaksasi terhadap tingkat nyeri Dismenore pada mahasiswi Fakultas Ekonomi Universitas Islam Lamongan.

\section{PEMBAHASAN}

Dari tabel 1.1. menunjukkan bahwa sebagian besar responden setelah diberi teknik relaksasi nafas tidak merasa nyeri lagi yaitu sebanyak 16 orang $(53,3 \%)$, nyeri sedang sebanyak 12 orang ( $40 \%$ ) dan hanya sebagian kecil yang masih mengalami nyeri Dismenore sedang yaitu sebanyak 2 orang $(6,7 \%)$. Dikatakan tidak nyeri lagi apabila responden mengatakan bahwa nyerinya sudah menghilang. Dan dikatakan nyeri sedang apabila secara subyektif responden mengatakan nyeri sedang dan secara obyektif responden mendesis, menyeringai, dapat menunjukkan lokasi nyeri, dapat mendeskripsikannya dan dapat mengikuti perintah dengan baik. Smeltzer \& Bare (2002) menyatakan bahwa tujuan teknik relaksasi napas dalam adalah untuk meningkatkan ventilasi alveoli, memelihara pertukaran gas, mencegah atelektasi paru, meningkatkan efesiensi batuk, mengurangj stress baik stress fisik maupun emosional yaitu menurunkan intensitas nyeri dan menurunkan kecemasan. 
Klien yang merasakan nyeri akan berusaha untuk menghilangkan rasa nyeri itu agar ketidaknyamanan yang dirasakan hilang dan aktivitas sehari-hari dapat tetap berjalan. Tujuan keseluruhan dalam pengobatan nyeri adalah mengurangi nyeri sebesarbesarnya dengan kemungkinan efek samping paling kecil (Price Sylvia A, 2006:1083).

Terdapat 2 metode untuk terapi nyeri yaitu farmakologi dan non farmakologi (Price Sylvia A, 2006:1083). Metode non farmakologi merupakan metode yang digemari masyarakat karena tidak membutuhkan obat atau alat tertentu serta mudah didapat dan mampu dilakukan sendiri.

Banyak cara untuk mengatasi sakit ini, salah satu cara yang digunakan adalah menggunakan teknik relaksasi nafas pada perut atau punggung bawah. Cara ini diharapkan mampu meringankan rasa nyeri sehingga aktivitas sehari-hari dapat berjalan dengan lancar.

Pada penelitian ini, mahasiswi tidak ada yang mendapatkan pengobatan, dimana dalam pemberian teknik relaksasi nafas tidak dipengaruhi oleh pengobatan lain sehingga observasi tingkatan nyeri Dismenore dapat dilakukan dengan mengurangi faktor perancu.

Uji statistik Wilcoxon Sign Rank Test menunjukkan nilai $p$ sign $<0,05$ dan $\mathrm{Z}$ hitung $>\mathrm{Z}$ tabel sehingga terdapat pengaruh teknik relaksasi nafas terhadap tingkat nyeri Dismenore pada mahasiswi Fakultas Ekonomi Universitas Islam Lamongan

Dismenore adalah nyeri menjelang atau selama menstruasi sehingga memaksa penderita untuk beristirahat. Penyebab masih belum diketahui pasti. Diduga terjadinya Dismenore karena endometrium dalam fase sekresi memproduksi prostaglandin $\quad\left(\mathrm{PGF}_{2} \propto\right) \quad$ yang menyebabkan vasokontriksi dan kontraksi miometrium (Ninik Dwi A, 2005).

Dismenore atau nyeri haid merupakan suatu gejala yang paling sering menyebabkan wanita atau penderita untuk istirahat dan meninggalkan pekerjaan atau cara hidupnya sehari-hari, untuk beberapa jam atau beberapa hari (Hanifa Wiknjosastro, 2005:229). Dengan melihat keadaan tersebut, maka penderita sangat penting untuk dilakukan penanganan agar aktivitas sehari-hari dapat berjalan dengan lancar.

Banyak cara untuk mengatasi sakit ini. Salah satu cara meringankan nyeri ini yaitu dengan teknik relaksasi nafas. Pemberian Teknik Relaksasi pernafasan yaitu dengan.Bernafas ritmik, pandangan fokus pada satu objek atau memejamkan mata dan melakukan inhalasi perlahan melalui hidung dengan hitungan satu sampai empat, hembuskan nafas melalui mulut secara perlahan dengan menghitung satu sampai empat (dalam hati), berkosentrasi pada sensasi pernafasan dan terhadap gambar yang memberi ketenangan, lanjutkan tehnik ini hingga terbentuk pola pernafasan ritmik.

Uterus dipersyarafi oleh sistem syaraf otonom yang terdiri dari syaraf simpatis dan parasimpatis. Jeffcoate (2002) mengemukakan bahwa Dismenorea ditimbulkan oleh ketidak seimbangan pengendalian sistem syaraf otonom terhadap miometrium. Pada keadaan ini terjadi perangsangan yang berlebihan oleh syaraf simpatis 
sehingga serabut-serabut sirkuler pada istmus dan ostium uteri internum menjadi hipertonik.Diharapkan teknik relaksasi dapat mengendalikan syaraf otonom sehingga dapat mengurangi nyeri.

Mekanisme terjadinya penurunan nyeri akibat dilakukan teknik relaksasi nafas karena Teknik relaksasi memberikan individu kontrol diri ketika terjadi rasa tidak nyaman atau nyeri, stress fisik dan emosi pada nyeri (Potter Patricia, 2006:1528)

Berdasarkan penelitian yang dilakukan di Fakultas Ekonomi Universitas Islam Lamongan pada mahasiswi yang mengalami Dismenore sebelum diberi teknik relaksasi nafas sebagian besar mengalami nyeri Dismenore ringan tetapi setelah diberi teknik relaksasi nafas ada penurunan nyeri yang sebagian besar mahasiswi sudah tidak merasa nyeri lagi. Hal ini disebabkan karena efek dari teknik relaksai sendiri yang dapat memberikan individu kontrol diri ketika terjadi rasa tidak nyaman atau nyeri, stress fisik dan emosi.

\section{KESIMPULAN}

Berdasarkan hasil analisa dan pembahasan penelitian, maka dapat disimpulkan bahwa :

1. Sebagian besar responden mengalami nyeri Dismenore ringan sebanyak $60 \%$ sebelum dilakukan teknik relaksasi.

2. Sebagian besar responden tidak merasa nyeri lagi sebanyak 53,3\% setelah dilakukan teknik relaksasi

3. Ada Pengaruh teknik relaksasi nafas terhadap tingkat nyeri Dismenore pada mahasiswi di universitas Islam Lamongan.

\section{SARAN}

1. Diharapkan dalam mengatasi nyeri Dismenore lebih baik diberikan teknik relaksasi nafas yang dalam pemberian teknik relaksasi nafaspun perlu diperhatikan teknik pernafasan yang benar

2. Bagi Institusi Pendidikan dan Lahan Penelitian

3. Perlu dibangun suatu ruangan khusus seperti UKS (Upaya Kesehatan Sekolah) sehingga apabila ada mahasiswi yang sakit dapat beristirahat dan mendapat pengobatan diruangan itu.

4. Bagi Profesi Kebidanan. Diharapkan dalam profesi kebidanan dapat mempertimbangkan untuk menerapkan teknik relaksasi nafas untuk mengatasi nyeri Dismenore. Karena hasil penelitian ini terdapat Pengaruh teknik relaksasi terhadap tingkat nyeri Dismenore

\section{DAFTAR PUSTAKA}

A. Aziz Alimul H.(2007). Metode Penelitian Keperawatan dan Teknik Analisis Data. Jakarta: Salemba Medika.

Ahmad Fauzi et.all.(2008). Nyeri Menstruasi (Dismenore). http/www: Minti@mweb.co.id. diakses tanggal 12 Mei 2016

Arif Mansjoer et.all.(2005). Kapita Selekta Kedokteran. Jakarta: Media Aesculapius.

Hanifa Wiknjosastro. (2005). Ilmu Kandungan. Jakarta: Yayasan Bina Pustaka Sarwono Prawirohardjo.

I.G.B.Manuaba.(2001). Kapita Selekta Penatalaksanaan Rutin Obstetri Ginekologi dan KB. Jakarta: EGC. 
Imcw.(2007). Dismenore (Nyeri Haid). http/www.blog dokter.net. diakses tanggal 12 Mei 2016.

Musrifatul U dan A. Aziz Alimul. (2006). Ketrampilan Dasar Praktik Klinik Kebidanan. Jakarta: Salemba Medika.

Ninik Dwi A.(2005). Dismenore Alias Nyeri Haid. http/www: Niexklaten.blogspot.com. diakses tanggal 12 Mei 2016

Posted.(2008). Konsep Dasar Nyeri. http/www: qittun.com.net.id. diakses tanggal 10 November 2008.

Potter, Patricia A., Alih bahasa Renata Komalasari.(2006). Buku Ajar Fundamental Keperawatan : Konsep, Proses dan Praktik. Jakarta: EGC

Price, Sylvia A., Alih bahasa Brahm U.(2006). Patofisiologi : Konsep Klinik Proses-Proses Penyakit. Jakarta: EGC.

Stevens, P.J.M.et.all., Alih bahasa J.A.Tomasowa.(2000). Ilmu Keperawatan. Jakarta: EGC.

Sugiono.(2006). Statistika untuk Penelitian. Bandung: Alfabeta.

Suharsini Arikunto.(2006). Prosedur Penelitian Suatu Pendekatan Praktik. Jakarta: Rineka Cipta.

Wahid I Mubarak.(2008). Buku Ajar Kebutuhan Dasar Manusia : Teori dan Aplikasi.Jakarta : EGC. 